\title{
Smiley or Frowney: The Effect of Emotions and Empathy Framing in a Downstream Water Pollution Game
}

\author{
Natalia V. Czap ${ }^{1}$, Hans J. Czap², Marianna Khachaturyan ${ }^{3}$, Mark E. Burbach ${ }^{4} \&$ Gary D. Lynne ${ }^{5}$ \\ ${ }^{1}$ Department of Social Sciences (Economics), University of Michigan-Dearborn, U.S.A. \\ ${ }^{2}$ Department of Management Studies, University of Michigan-Dearborn, U.S.A. \\ ${ }^{3}$ Department of Agricultural Economics, University of Nebraska-Lincoln, U.S.A. \\ ${ }^{4}$ School of Natural Resources, University of Nebraska-Lincoln, U.S.A. \\ ${ }^{5}$ Department of Agricultural Economics and School of Natural Resources, University of Nebraska-Lincoln, \\ U.S.A.
}

Correspondence: Natalia V. Czap, Department of Social Sciences (Economics), University of Michigan-Dearborn, 4901 Evergreen Rd., Dearborn, MI 48103, U.S.A. Tel: 1-313-583-6354. E-mail: nczap@umich.edu

Received: November 17, 2012

Accepted: January 2, 2013

Online Published: February 22, 2013

doi:10.5539/ijef.v5n3p9

URL: http://dx.doi.org/10.5539/ijef.v5n3p9

\begin{abstract}
Common-pool resources and other shared resources frequently suffer from overextraction/overuse and associated negative externalities. In this paper we design a framed laboratory experiment on downstream water pollution to investigate (a) the importance of empathy vs. self-interest framing in determining the behavior of upstreamers regarding the negative externalities, and (b) the potential of downstreamers to influence the choices of upstreamers using non-monetary sanctions and rewards, alleviating the need for intervention by the local governments and regulatory institutions. Our results show that empathy framing has a much more significant impact on individual behavior than self-interest framing. Overall subjects behaved more profit-oriented in the self-interest framing and more egalitarian in the empathy framing. Lastly, negative emotional feedback is a powerful tool for changing behavior of subjects towards more environmentally friendly actions. Interestingly, positive emotional feedback is counterproductive for that. In general our results indicate that explicit emotional feedback, even though not expressed by everyone, works to the same degree as the implicit appeal to emotions through framing.
\end{abstract}

Keywords: empathy framing, self-interest framing, emotional feedback, water pollution, environmental experiment, reward and punishment

\section{Introduction}

The problem of shared resources, especially common pool resources (CPRs) (e.g., fisheries and forests), has been studied for decades. In case of CPRs, if the users are driven solely by self-interest and do not cooperate/coordinate their actions, overextraction occurs. However, over the years experimental researchers (see, among others, Ostrom \& Walker, 1991; Sally, 1995; Balliet 2010; Cardenas et al., 2000; Ostrom, 2010) showed in the laboratory and in the field that users of CPRs are not always driven by strict self-interest and often manage to prevent the overuse (Note 1) of resources through (self-imposed) regulations and sanctions.

In the context of other shared resources unchecked self-interest and lack of cooperation/coordination may lead to negative externalities through pollution in addition to/instead of overextraction. For many flowing water resources (such as rivers and creeks) usage creates an upstream-downstream problem. If the upstreamers are motivated exclusively by self-interest and profit maximization, they are likely to impose negative externalities (in the case of farmers, for example, water pollution through chemical runoffs and soil erosion) on individuals living downstream. In contrast, if the upstreamers are motivated by empathetic considerations towards nature and/or the downstreamers, they may reduce negative externalities by undertaking costly actions.

This situation raises two interesting empirical questions. The first question asks whether there is a difference in behavior of the upstreamers, if their decision is framed as a decision mainly regarding profit maximization, taking into account the externalities of pollution, versus if their decision is framed as a decision mostly on preserving the 
cleanliness of water resources, taking into account profit maximization. The former case brings to the forefront self-interest considerations conditioned by empathy, whereas the latter emphasizes empathetic considerations tempered by self-interest.

The second question deals with the potential of downstreamers to influence the behavior of upstreamers without involvement of local governments and regulatory institutions via non-monetary sanctions and rewards (such as positive/negative word-of-mouth, campaigns to increase awareness about the problem, display of social (dis)approval, etc.). If such sanctions work and are powerful enough to significantly change the behavior of the upstreamers, then public policies and environmental organizations should focus on providing venues that facilitate the flow of information from downstreamers to upstreamers and communication between them.

In this paper we design a downstream water pollution game to investigate these two questions. The rest of the paper is structured as follows: Section 2 discusses the theoretical underpinning of our study, Section 3 describes the experimental design and hypotheses, Section 4 analyses the results, Section 5 concludes.

\section{Framing and (Dis)Approval Effects}

\subsection{Framing Effects}

Experimental economists are rightfully concerned about the potential framing effect of instructions. The majority of economic experiments is framed neutrally and presents a context-free environment to minimize social cues of how one should behave and to minimize the influence of homegrown values on individual decisions in the laboratory. Neutral wording allows researchers to retain control over the factors that influence subjects' choices. However, in certain contexts it is impossible to avoid framing without making the task irrelevant. A number of studies examine the effect of framing in the instructions on individual behavior in the context of corruption (Abbink \& Hennig-Schmidt, 2006; Barr \& Serra, 2009), public goods games (Andreoni, 1995; Cookson, 2000; Park, 2000; Fujimoto \& Park, 2010; Cubitt, Drouvelis \& Gächter, 2011; Cubitt, et al. 2011), sequential bargaining games (Brosig et al., 2003), and altruistic giving in dictator games (Duffy \& Kornienko 2010). The existing experiments manipulating the framing of instructions can be separated roughly into two categories: procedural-oriented framing (which compares the different ways of representing the problem, e.g. neutral context vs. contextualized, or the type of payoff presentation) and priming-oriented framing (which suggests a particular value judgment, e.g. selfish vs. altruistic, positive vs. negative, take vs. give).

The effect of procedural-oriented framing is ambiguous. In bribing games, Abbink \& Hennig-Schmidt (2006) showed that there is no difference between individual behavior exposed to neutral and framed/contextualized instructions, while Barr \& Serra (2009) reported the opposite finding. In public goods games, Cookson (2000) found that changing the presentational variables (e.g. the formulation of the payoff function or the type of comprehension task) has a strong effect on experimental results. In sequential bargaining games, Brosig et al. (2003) reported the existence of a hot (ordinary sequential manner, i.e. the subjects respond to the choices made by their partner) versus cold effect (strategy method, i.e. the subjects submit a complete set of choices before play commences) (Note 2), while earlier research by Brandts \& Charness (2000) did not find it.

The effect of priming-oriented framing is more robust. Andreoni (1995) and follow-up studies by Park (2000) and Fujimoto \& Park (2010) demonstrated that subjects contributed significantly more to a public good under positive framing (investing in a public good) compared to negative framing (investing in a private good). Along the same lines Cubitt et al. (2011) showed that there is a framing effect when expressing moral judgment about contributions, with free-riding in a Give treatment being condemned more strongly than in a Take treatment. However, when one controls for contributions, monetary punishment and self-reported emotions are not sensitive to Give versus Take manipulation. In the dictator game Duffy \& Kornienko (2010) showed that the subjects give more in an altruistic treatment (dictators are ranked in descending order according to the amount they give) as compared to a control and to a selfish treatment (dictators are ranked in descending order according to the amount they keep for themselves).

This paper contributes to the ongoing discussion in the experimental literature about framing effects by examining the priming-oriented framing effects in the context of environmental protection.

\subsection{Social (Dis)Approval through Reward/Punishment and Emotions}

Rewards and punishments are used to express social (dis)approval and increase fairness and cooperation in social dilemmas and situations involving distribution of income and assets. Experimental papers report that punishment is more effective than rewards in dictator games (Andreoni et al., 2003), public goods games (Dickinson, 2001; Sefton et al., 2008; Sutter et al., 2010, but not in Walker \& Halloran, 2004), and common pool resource games (van Soest \& Vyrastekova, 2006). Furthermore, Andreoni et al. (2003) show that both methods are complements rather 
than substitutes in enforcing the ideals/norms and reaching the specific objectives. This effect is particularly strong when the punishments and rewards are decided and implemented by the group members rather than by an exogenous institution (Sutter et al., 2010).

Actions of individuals, both helping and hurting, are strongly linked to positive and negative emotions of the affected party (Offerman, 2002; Bosman \& van Widen, 2002; Xiao \& Houser, 2005). Rewards and punishments represent positive and negative reciprocity and as such they are behavioral means to express positive and negative emotions. According to Fehr \& Gächter (2002, p.139) negative emotions are the proximate sources of punishment: "Free riding may cause strong negative emotions among the cooperators and these emotions, in turn, may trigger their willingness to punish the free riders." Similarly, "costly punishment might itself be used to express negative emotions" (Xiao \& Houser, 2005, p.7398); anger (regarding norm violations) and guilt are sufficient to induce punishment (Nelissen \& Zeelenberg, 2009), and a higher intensity of reported positive/negative emotions increases the likelihood of reward/punishment (Offerman, 2002). As positive and negative emotions are expressed in terms of reward and punishment, they, in turn, may also trigger emotions in a receiving party and cause a second round of reciprocation.

To the best of our knowledge there is no systematic investigation of the impact of expressed negative and (explicit) positive emotions (not just an absence of disapproval) by the affected party back on the affecting party. This link does not seem to be straightforward. Hopfensitz \& Reuben (2009) showed that the effectiveness of negative emotions, expressed by the punishing party, depends on the reaction of those who are punished. Specifically, if the expressed negative emotions lead to anger this may cause retaliation, whereas if shame and guilt are the result, it may restrain the desire of the punished party to fight back (Hopfensitz \& Reuben, 2009). It is very plausible that the effect of positive emotions will be similarly contradictory. Positive emotions, expressed by the rewarding party, can trigger positive reciprocity in the rewarded party and further increase cooperation and altruistic actions. At the same time positive emotions signal that the rewarding party is satisfied with the outcome, which may encourage the rewarded party to be a little more selfish next time around and test a lower threshold of acceptability.

In this paper we conduct a 2-round game in which after the first round the affected party can express their emotions regarding the outcome/behavior to the affecting party. This allows testing how much this emotional response will influence the behavior of the affecting party in the second round.

\subsection{Monetary versus Non-Monetary Rewards and Punishments}

Several experimental studies demonstrate that non-monetary sanctions and rewards can be as efficient as monetary incentives in inducing cooperation and fair outcomes. Masclet et al. (2003) showed that contribution levels to public goods from both monetary and non-monetary sanctions (expressing a degree of disapproval) are similar, with non-monetary sanctions working better under partner, as compared to stranger matching. Bochet et al. (2006) found that both face-to-face and verbal communication through a chat room (with anonymity and with no facial expressions) have stronger effects on increasing contributions to public goods, than monetary punishment. Xiao \& Houser (2009) showed in an ultimatum bargaining game that monetary punishment is more effective than informal sanctions (written messages) in promoting fairness. However, their results, taken together with Xiao \& Houser (2005), indicate that as a sanctioning mechanism expressing emotions is overall more beneficial for social welfare than costly monetary punishment, as it eliminates (pecuniary) welfare losses. López-Pérez \& Vorsatz (2010) demonstrated that approval/disapproval (Note 3 ) feedback fosters cooperation in the prisoner's dilemma games as it increases awareness about the other's feelings and because individuals are disapproval-averse. However, the effect of positive and negative feedback is not the same. According to Dugar (2010) costless ratings of disapproval assigned by group members lead to the most efficient equilibrium in the coordination game, whereas ratings of approval cause just the opposite. Finally, Noussair \& Tucker (2005) found that monetary and non-monetary punishments are complements rather than substitutes as they appeal to different populations and at different time horizons.

In our experiment we test the effectiveness of non-monetary reward and punishment through a discrete and standardized expression of emotions in inducing a more equal distribution.

\section{Experimental Design and Procedures}

\subsection{Design of the Downstream Water Pollution Game}

We model the environmental protection context by using a framed laboratory experiment on downstream water pollution. This is a three-player game. The first player is a farmer performing agricultural operations upstream (henceforth called Upstream Farmer or UF) who decides on the usage of conservation technology. This technology (called conservation tillage or CT, see Note 4) lessens the negative impact of farming on the water 
quality in downstream rivers and lakes, but is more costly than the alternative intensive tillage (IT, see Note 5) for the UF. The descriptions of agricultural technologies presented to the subjects in the instructions were significantly modified and simplified to avoid any misunderstanding and ambiguity. The UF's payoff $\left(\pi_{U F}\right)$ in tokens depends negatively on her usage of conservation technology, specifically the amount of land (out of her endowment of 500 acres) she places under conservation tillage $\left(C T_{U F} \in[0,500]\right)$ :

$$
\pi_{U F}=500+2 *\left(500-C T_{U F}\right)
$$

The second player is an individual who is drawing her drinking water from the lakes and rivers downstream (henceforth called Downstream Water User or DWU) and incurs the cost of cleaning the polluted water. The DWU's payoff $\left(\pi_{D W U}\right)$ in tokens positively depends on the cleanliness of the downstream lake:

$$
\pi_{D W U}=500+10 *(\% \text { Cleanliness of the Lake })
$$

The third player has a dual role: he performs farming operations upstream (thus deciding on the usage of conservation technology) and, at the same time, lives on farms tied to rural water supply systems that draw water from the very stream passing through his own farmland, and is, hence, using drinking water from downstream (those individuals are called Upstream Farmer/ Downstream Water User or UF/DWU). The UF/DWU's payoff $\left(\pi_{U F / D W U}\right)$ in tokens negatively depends on his usage of conservation technology $C T_{U F / D W U} \in[0,500]$, and positively on the cleanliness of the lake:

$$
\pi_{U F / D W U}=2 *\left(500-C T_{U F / D W U}\right)+10 *(\% \text { Cleanliness of the Lake })
$$

The cleanliness of the lake is determined as the proportion of land placed under conservation tillage by the two farmers (UF and UF/DWU, see Note 6):

$$
\% \text { Cleanliness of the Lake }=\frac{C T_{U F}+C T_{U F / D W U}}{500+500} * 100 \%
$$

The game represents a zero-sum game, where the total group payoff is independent of the payoff distribution: the three players were sharing 3000 tokens. The structure of the payoffs was chosen so that each of the three players gets an equal payoff of 1000 tokens if the farmers choose $C T_{U F}=C T_{U F / D W U}=250$ acres, which leads to $\%$ Cleanliness of the Lake $=50 \%$ (for selected combinations of strategies and payoffs see the top half of Table 1).

The Nash equilibrium (conditional on the standard assumption of profit-maximizing behavior) for both UF and UF/DWU is to choose a zero level of conservation technology since for the UF/DWU the return on conservation

\begin{tabular}{|c|c|c|c|c|}
\hline \multirow[b]{2}{*}{ EMPATHY FRAME } & & \multicolumn{3}{|c|}{ Upstream Farmer/ Downstream Water User } \\
\hline & & $\mathrm{CT}_{\mathrm{UF} / \mathrm{DWU}}=500$ & $\mathrm{CT}_{\mathrm{UF} / \mathrm{DWU}}=\mathbf{2 5 0}$ & $\mathrm{CT}_{\mathrm{UF} / \mathrm{DWU}}=0$ \\
\hline \multirow{3}{*}{ Upstream Farmer } & $\mathrm{CT}_{\mathrm{UF}}=500$ & $500,1000,1500$ & $500,1250,1250$ & $500,1500,1000$ \\
\hline & $\mathrm{CT}_{\mathrm{UF}}=\mathbf{2 5 0}$ & $1000,750,1250$ & $1000,1000,1000$ & $1000,1250,750$ \\
\hline & $\mathrm{CT}_{\mathrm{UF}}=0$ & $1500,500,1000$ & $1500,750,750$ & $1500,1000,500$ \\
\hline $\begin{array}{c}\text { SELF-INTEREST } \\
\text { FRAME }\end{array}$ & & $\mathrm{IT}_{\mathrm{UF} / \mathrm{DWU}}=500$ & $\mathrm{IT}_{\mathrm{UF} / \mathrm{DWU}}=\mathbf{2 5 0}$ & $\mathrm{IT}_{\mathrm{UF} / \mathrm{DWU}}=0$ \\
\hline \multirow{3}{*}{ Upstream Farmer } & $\mathrm{IT}_{\mathrm{UF}}=500$ & $1500,1000,500$ & $1500,750,750$ & $1500,500,1000$ \\
\hline & $\mathbf{I T}_{\mathrm{UF}}=\mathbf{2 5 0}$ & $1000,1250,750$ & $1000,1000,1000$ & $1000,750,1250$ \\
\hline & $\mathrm{IT}_{\mathrm{UF}}=0$ & $500,1500,1000$ & $500,1250,1250$ & $500,1000,1500$ \\
\hline
\end{tabular}
technology is twice the return on the lake cleanliness. In this sense the decision of UF and UF/DWU to use non-zero levels of conservation technology is similar to altruistic giving in a dictator game.

Table 1. Selected strategies and payoffs of the players

Description: The table provides selected decisions of the UF and UF/DWU and their outcomes in EMPATHY FRAME and SELF-INTEREST FRAME treatments. The numbers in each cell represent the payoffs of the three players given the choices by UF and UF/DWU. The payoffs are written in the following order: UF, UF/DWU, DWU.

\subsection{Experimental Treatments}

We implemented three manipulations: two framing (empathy and self-interest) treatments using loaded language and one no-framing treatment using neutral language. In the framing treatments the players were referred to as UF, DWU, and UF/DWU. They were presented with the description of the upstream-downstream situation and asked to make decisions regarding the choice of tillage on their land. In the NEUTRAL FRAME treatment the players were 
referred to as Player 1, 2, and 3, and were presented with a situation described in a neutral language in which they had to allocate chips between Options A and B.

The two framing treatments differed in how the situation was presented to the subjects. In the EMPATHY FRAME the context was described from the point of view empathetic to the DWU and the participants had to choose the level of conservation tillage that will affect the cleanliness of the lake as discussed in the previous subsection. According to Singer (2009, p.252) "when we empathize, we share another person's feelings". In line with that our empathy (Note 7) framing stresses the effect of the farmer's choice on the water user's outcomes and through that increases the understanding and sensitivity of the former to the feelings of the latter.

In the SELF-INTEREST FRAME the context was described from a self-interest/profit-maximizing point of view and the participants had to choose the level of intensive tillage (IT, less environmentally friendly technology) that will affect the pollution of the lake. The description underlining self-interest reflects the traditional public policy framing in which monetary profit-maximization by farmers is a default assumption of conservation policies. This thus poses a natural comparison point for the empathy frame.

The payoff of the three players in the SELF-INTEREST FrAME was mirroring the payoffs in the EMPATHY Frame and was calculated based on IT and \% pollution of the lake. The decisions of the farmers in two treatments can be converted as: $C T=500-I T$ and $\%$ Cleanliness of the Lake $=100 \%-\%$ Pollution of the Lake. Similar to the EMPATHY FRAME, in SELF-INTEREST FRAME the players get an equal payoff of 1000 tokens if the farmers choose $I T_{U F}=I T_{U F / D W U}=250$ acres which leads to \% Pollution of the Lake $=50 \%$ (for selected combinations of strategies and payoffs see the bottom half of Table 1). To simplify the analysis, all data was converted and the results below will be discussed in terms of CT and the cleanliness of the lake.

\subsection{Rounds of the Game and Emotional Feedback}

The game was played for two rounds. In each round the UF and UF/DWU (or Player 1 and 2 in the NEUTRAL FRAME manipulation) chose the acreage under CT (EMPATHY FRAME) or IT (SELF-INTEREST FRAME) or the number of chips to place into Option B (NEUTRAL FRAME). Next, the DWU received information about the level of cleanliness or pollution of the lake, but not the actual CT/IT choices of UF and UF/DWU (Note 8).

At the end of the first round the DWU was given the opportunity to express her positive or negative emotions by sending emoticons: a smiley/happy face $;$;) or a frowney/unhappy face $: ;$ to both farmers (Note 9 ). Sending each face was costly for the DWU (50 tokens). If the emoticons were sent, they appeared on the screen of both farmers (Figure 1a, b). In order to minimally pollute the data, the payoffs of subjects were not shown to them until after the game. The UF and the DWU could have potentially calculated their earnings, but not the UF/DWU as she was not aware of the cleanliness of the lake. We specifically did not want to show the cleanliness of the lake to the $\mathrm{UF} / \mathrm{DWU}$, as from the cleanliness they could have inferred the CT of the UF, and this knowledge could have affected their decisions in the second round. After that the game proceeded to the second (and last) round.
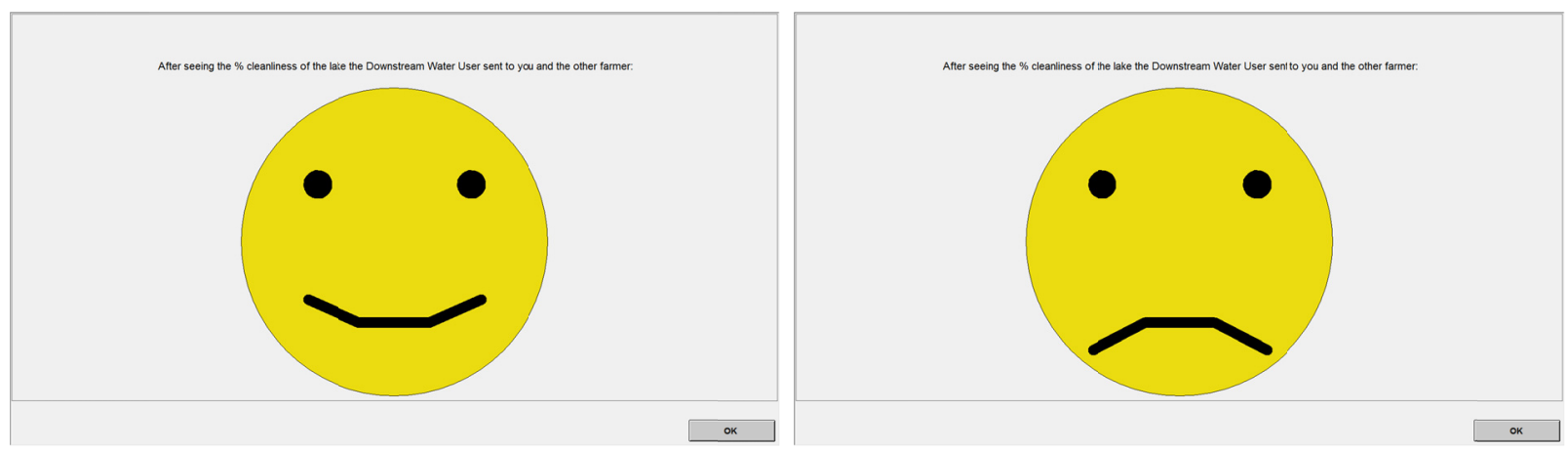

Figure 1. a, b. Smiley and frowney emoticons received by the farmers from the DWU

Description: These are the z-Tree screen shots that were shown to the UF and UF/DWU if the DWU, after observing the level of cleanliness/pollution of the lake, sent them (a) - a smiling or (b) - a frowning face.

Although one-shot games are preferable for this type of analysis because they eliminate strategic considerations of players in the repeated game context, we believe that our two-round game achieves the same objective. Neither within one round nor across the two rounds were there any strategic considerations: the decision of the UF affects the payoff of the UF/DWU, but not vice versa; the decision of the UF affects the payoff of the DWU, but not vice 
versa; finally, the decision of the UF/DWU affects the DWU's payoff, but not vice versa (in the instructions the players were not told that the DWU will be able to send an emotional feedback and, thus, could not have reacted strategically to avoid/solicit it).

\subsection{Hypotheses}

The hypotheses deal with the framing effect, the difference between the decisions of UF and UF/DWU, and the effect of the discrete emotions expressed by the DWU towards the decisions of the UF and the UF/DWU.

The framing effect, if present, will affect two decisions: the usage of conservation technology by the farmers and the likelihood to send a smiley or frowney emoticon by the water user. The null hypothesis is that there is no difference neither between the EMPATHY and SELF-INTEREST FRAME nor between the loaded manipulations and the NeUtral Frame. For the farmers' decisions, the alternative hypothesis is that the framing affects farmers' choice of the CT level and the following pattern will be observed:

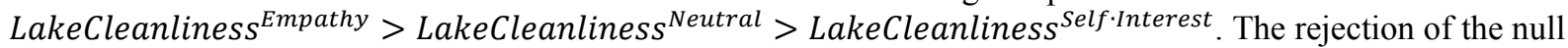
hypothesis would be in line with findings reported in similar situations by Andreoni (1995), Park (2000), Fujimoto \& Park (2010), Cubitt et al. (2011), and Duffy \& Kornienko (2010). As for the likelihood to send an emoticon, the alternative hypothesis is that the loaded framing will result in a higher propensity to send a face than the NEUTRAL FRAME, and there will be relatively more smileys in the EMPATHY FRAME and relatively more frowneys in the SELF-INTEREST FRAME. However, in the case of emotional response, it is reasonable to expect that the null hypothesis will not be rejected as the DWU is more likely to be affected by the lake cleanliness and react on that, rather than on framing. This expectation is supported by the findings of Cubitt, Drouvelis \& Gächter (2011), who showed that the propensity to punish in the public goods game is driven by the contributions rather than by the framing effect.

From the self-interest perspective and even accounting for empathy towards the DWU (since both farmers equally affect the lake cleanliness), the decisions of UF and UF/DWU about conservation technology are conceptually equivalent. The null hypothesis is that there will be no difference between the CT chosen by the two farmers within one treatment. The alternative hypothesis is that within one treatment $C T_{U F / D W U}>C T_{U F}$. The UF/DWU, by the nature of the situation, is better able to empathize, to "walk-in-the-shoes" of the DWU, while the UF can only imagine how it would feel like. In that sense, the position of the UF/DWU is similar to a situation in which people play non-symmetric games with switching roles [following the discussion by Brosig et al. (2003) about the comparison of simple bargaining game and a game with switching roles]. The UF/DWU is more likely to engage in self-reflection and empathetic considerations and will have more realistic beliefs on how it feels like being a DWU. The beliefs of the UF, on the other hand, may be less realistic and, thus, their decisions are expected to be less empathetic. In this case we would expect to reject the null hypothesis in favor of the alternative. A rejection would be corroborated by the difference between bargaining and dictator games in which the players are switching roles and the games in which they do not [see the discussion in Brosig et al. (2003, p.85) comparing their results to Brandts \& Charness (2000)].

Finally, consider the effect of positive or negative emotions expressed by the DWU on the decisions of the UF and UF/DWU in the second round. The null hypothesis is that the emotional response will have no effect on the farmer's choices. The alternative hypothesis is that both smiley and frowney faces will encourage the farmers to increase their CT usage, with frowney being more effective in achieving that goal. As positive and negative emotions are shown to be linked to monetary rewards and punishments (Offerman, 2002; Bosman \& van Widen, 2002) and those monetary rewards and punishments affect behavior, it is reasonable to expect that we will reject the null hypothesis. Along the same lines, as punishments were shown to be more effective than rewards (Andreoni et al., 2003; Dickinson, 2001; Sefton et al., 2008; Sutter et al., 2010; van Soest \& Vyrastekova, 2006), we would expect that expressing negative emotions will increase CT usage more than expressing positive emotions.

\subsection{Procedures and Subjects}

Each subject was assigned a 5-digit random number to assure anonymity. The experimental instructions were read to the participants aloud and also presented on their computer screen. In addition, each subject received two handouts: a $11 \mathrm{X} 11$ payoffs table with some of the possible combinations of strategies and a list of formulas to calculate the payoffs. Following the instructions the experimenter answered questions and the participants were presented with a quiz checking their understanding of the instructions and the calculation of the payoffs. After all subjects successfully completed the quiz they proceeded to the experiment.

In total, 216 subjects participated in the experiment: 84 in each of the EMPATHY and SELF-INTEREST FRAME and 48 in the NEUTRAL FRAME treatments, resulting in 28, 28 and 16 independent observations per treatment respectively. All subjects were recruited at the University of Nebraska-Lincoln (the majority were students, $45 \%$ females, 
average age was 27 years). The experiment was conducted in the Experimental and Behavioral Economics Laboratory. All sessions were computerized and administered using the software z-Tree (Fischbacher, 2007). Each session was 70-100 minutes long. The tokens that the participants earned during the experiment (sum of payoffs in both rounds) were converted into dollars ( $\$ 1=70$ tokens) and paid to the participants privately in cash, with average earnings of $\$ 28.9$ (Note 10 ).

\section{Experimental Results and Discussion}

\subsection{Decisions of the UF and UF/DWU in the First Round}

\subsubsection{Lake Cleanliness and Conservation Technology}

The decision of the farmers about the conservation technology led to quite high levels of lake cleanliness in the first round: $46.3 \%, 34.7 \%$ and $29.4 \%$ in the EMPATHY, NeUTRAL, and SELF-INTEREST FrAME, respectively. This result is in line with what one would expect given the findings reported in the previous literature, as discussed above. According to the non-parametric Kruskal-Wallis test $\left(\chi^{2}(2)=7.74\right.$, p-value $\left.=0.02\right)$ there is a significant difference between the treatments. The analysis of each pair of treatments using the Mann-Whitney-Wilcoxon rank-sum test indicated that the only significant (at 5\% or less) difference is between the cleanliness in the EMPATHY and the default position represented by the SELF-INTEREST FRAME ( $\mathrm{p}=0.00899)$.

Result 1. Empathy framing leads to higher usage of conservation technology as compared to self-interest framing.

Based on the Kruskal-Wallis test the treatment effect on the levels of conservation tillage chosen by the UF and the UF/DWU (Figure 2) was statistically significant different $\left(\chi^{2}(2)=12.26\right.$, p-value $=0.0023$ ). Similarly to above, the Mann-Whitney-Wilcoxon rank-sum test showed a significant difference only between the CT by UF in the EMPATHY and SELF-INTEREST FRAME ( $\mathrm{p}=0.0005)$. As for the CT levels that were chosen by the UF/DWU, neither the Kruskal-Wallis nor the Mann-Whitney-Wilcoxon tests indicated statistically significant differences between the treatments.

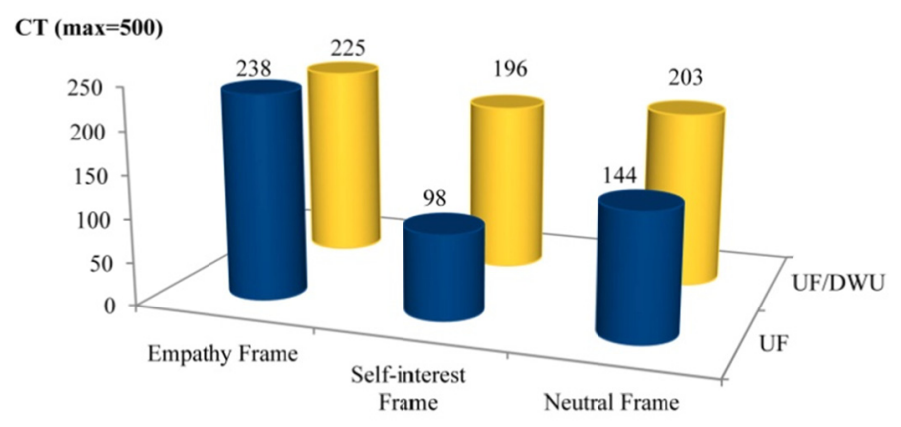

Figure 2. Conservation Tillage (CT) chosen by the farmers in round 1

Description: The figure reflects the decisions of the UF and UF/DWU in Round 1 depending on the treatment and the type of the farmer. The farmers could place a maximum of 500 acres under Conservation Tillage. If both farmers place 250 acres for CT, all three players (UF, UF/DWU, and DWU) will get an equal payoff of 1000 tokens.

Overall this leads to the rejection of the null hypothesis regarding the absence of a framing effect on the lake cleanliness, with the emphasis that the difference in the lake cleanliness is driven by the UF's behavior. In this game the ratio of UF to UF/DWU is 1:1, and one would expect more pronounced differences between the manipulations the more the ratio in the community is skewed towards UF.

\subsubsection{Difference between UF and UF/DWU Choices}

The hypothesis regarding no difference between the decisions of UF and UF/DWU is rejected in one treatment and not rejected in two others. As is evident from Figure 2 there is hardly any difference between the levels of conservation tillage chosen by UF and UF/DWU in the EMPATHY FRAME. The 238 and 225 acres of land placed under the conservation tillage by UF and UF/DWU resulted in approximately equal payoffs for UF, UF/DWU, and DWU: 1024, 1013, and 963 tokens respectively. In the NEUTRAL FrAME the difference is noticeable (203 for UF/DWU and 144 for UF), however, not statistically significant according to the Mann-Whitney-Wilcoxon 
rank-sum test. SELF-INTEREST FRAME is the only case where the difference is statistically significant (Mann-Whitney-Wilcoxon rank-sum test $p$-value $=0.0369$ ) with UF/DWU placing 196 and UF placing 98 acres under conservation tillage.

Result 2. The forced "walking-in-the-shoes-of-others" tempers self-interested considerations.

This is in line with the conjecture by Singer \& Fehr (2005, p.343) that "the very ability to empathize may also undermine purely self-interested choices". This result also provides further support for the dual-interest and metaeconomic framework (Hayes \& Lynne, 2004; Lynne, 2006). It suggests that people are imagining themselves in the state of others in the community, and, as a result, are conditioning their own internalized pursuit of self-interest with the shared other-interest. This result, taken together with the aforementioned framing effect, suggests that under the self-interest frame raising the stakes of the upstreamers in the downstream water quality (such as the case with UF/DWU) inspires a more equal payoffs distribution with a magnitude comparable to empathy framing. In that sense salient incentives are as powerful as empathy considerations. In contrast, under the empathy frame this strategy does not lead to a significant change in behavior, because the subjects already have reached a near equitable distribution and "walking-in-the-shoes-of-others" does not need to "temper" any longer.

\subsection{Expression of Emotions by the DWU}

Downstreamers demonstrated substantial willingness to (costly) express their emotions: smiley or frowney emoticons were sent in more than $60 \%$ of the cases in the framing treatments (consistent with imposing monetary rewards and punishments in the Carrot-Stick treatment in Andreoni et al. (2003)) and 56\% of the cases in the neutral scenario. In the SELF-INTEREST FRAME treatment 9 out of 10 emoticons sent were frowneys, while in the EMPATHY FRAME only 6 out of 10 were frowneys (Figure 3).

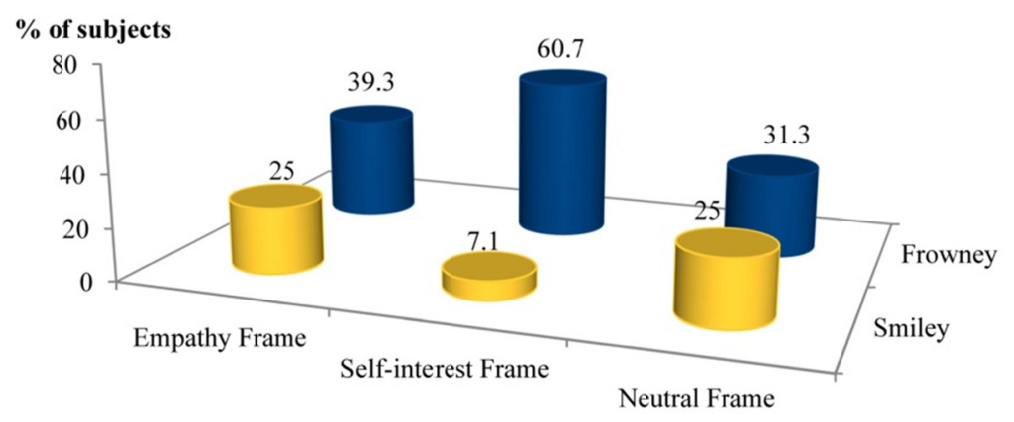

Figure 3. Percentage of DWUs sending an emotional feedback

Description: The figure reflects the proportion of the DWUs who sent to the farmers a smiley or a frowney in Round 1 in each of the three treatments. Sending a face cost the DWU 50 tokens.

Positive emotions were expressed when the cleanliness of the lake was $50-70 \%$, depending on the treatment (Figure 4), suggesting that the distribution of payoffs has to be biased in favor of the DWU to trigger their positive emotions through $:$. There is also a spread of about 20 percentage points of lake cleanliness between the treatments in the cases when emotions were not expressed. However, there is a consensus regarding what must be punished by negative emotions - a cleanliness of the lake of, on average, between $19.7 \%$ and $26.8 \%$ will result in $:$ being sent.

To test for the statistical significance of the differences between the treatments we constructed multinomial logit regressions in which we controlled for the cleanliness of the lake (Table 2). The dummies for treatment in the linear form (Model 2) as well as an interaction with cleanliness (Model 3) are not significant. Given this result we cannot reject the null hypothesis on the absence of a framing effect on sending emotional feedback. In line with the findings reported by Cubitt, Drouvelis \& Gächter (2011), in our experiment emotional punishments and rewards are based on the more immediate payoff-relevant information (such as lake cleanliness), rather than on framing. 


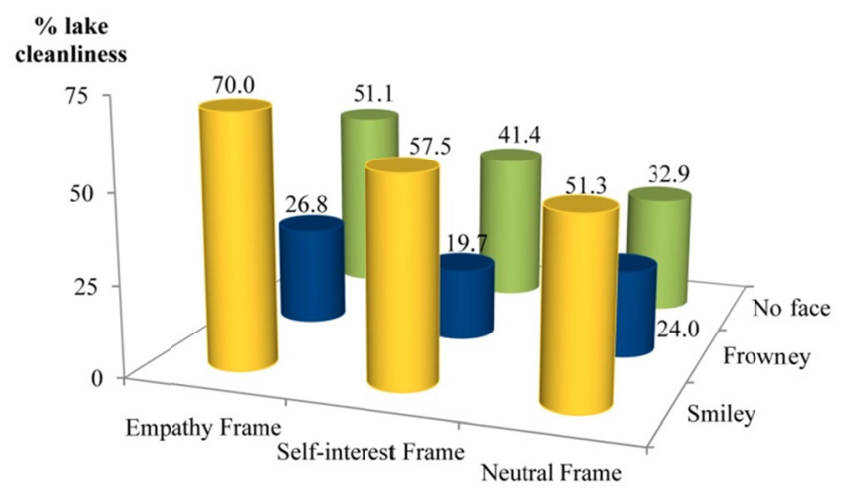

Figure 4. Average cleanliness of the lake that triggers emotion expression by treatment

Description: The figure reflects the level of cleanliness of the lake in Round 2 in the three treatments tabulated by the face sent by the DWU to the farmers.

Table 2. Multinomial logit model with the dependent variable "Positive or Negative Emotions" (:) or $(*)$

\begin{tabular}{|c|c|c|c|}
\hline & Model 1 & Model 2 & Model 3 \\
\hline \multicolumn{4}{|l|}{ INTERCEPT } \\
\hline ;) & $-3.19 * * *$ & $-2.80 * *$ & $-3.29 * * *$ \\
\hline : & $2.30 * * *$ & $1.58 *$ & $2.55 * * *$ \\
\hline \multicolumn{4}{|l|}{ CLEANLINESS } \\
\hline$+;$ & $4.77 * *$ & $5.46^{* *}$ & $6.08^{* *}$ \\
\hline :) & $-6.41 * * *$ & $-7.17 * * *$ & $-9.98 * * *$ \\
\hline \multicolumn{4}{|c|}{ EMPATHY FRAME } \\
\hline ;:) & & -0.79 & \\
\hline : & & 1.33 & \\
\hline \multicolumn{4}{|c|}{ SELF-INTEREST FRAME } \\
\hline ;) & & -1.53 & \\
\hline : & & 1.22 & \\
\hline \multicolumn{4}{|c|}{ CLEANLINESS $x$ EMPATHY FRAME } \\
\hline ;) & & & -0.95 \\
\hline (:) & & & 3.30 \\
\hline \multicolumn{4}{|c|}{ CLEANLINESS x SELF-INTEREST FRAME } \\
\hline ;) & & & -2.37 \\
\hline (:) & & & 3.73 \\
\hline Log-Likelihood & -56.7 & -53.6 & -54.6 \\
\hline Nagelkerke $R^{2}$ & 0.45 & 0.50 & 0.49 \\
\hline
\end{tabular}

Description: Significance levels: *** $-1 \%, * *-5 \%, *-10 \%$. The table shows the result of the regressions estimating the influence of the treatment and the level of lake cleanliness on the expression of emotions (smiley or frowney) by the DWU.

Cleanliness of the lake is the only variable that affects the expression of emotions (Table 2). Positive emotions (in the form of ()) are expressed significantly (at 5\%-level) less often than no emotions, as is evident from the negative sign in front of INTERCEPT for $;$ in all three models. However, the downstreamers are quite eager to express their negative emotions (positive and significant coefficient in front of INTERCEPT for $*$ ). The cleaner the lake is, the higher is the probability that the DWU expresses positive emotions (in Model 1, for lake cleanliness the odds ratio of sending (:) over not expressing emotions is 1.049 , see Note 11). Consequently, the cleaner the lake is, the lower is the probability that the DWU expresses negative emotions (in Model 1, for lake cleanliness the odds ratio of sending $: 0$ over not expressing emotions is 0.938 ).

Result 3. The expression of emotions is driven by the outcomes and it is independent of framing.

These findings suggest that subjects are eager to express directly their emotions even though this expression is costly for them. Positive emotions are expressed when the outcomes are in their favor (higher than equal share). Negative emotions are expressed when the resulting payoff falls below $30 \%$ of the equal payoff. Expression of emotion is motivated by the payoff, rather than by framing. 


\subsection{Effectiveness of Emotions: The UF and UF/DWU Choices in the Second Round}

The comparison of the effectiveness of positive and negative emotions in promoting environmentally conscious behavior led to (perhaps) an unsurprising result: the expression of negative emotions worked well and better than the expression of positive emotions. This is in line with findings that punishments are more effective than rewards (Andreoni et al., 2003; Dickinson, 2001; Sefton et al., 2008; Sutter et al., 2010; van Soest \& Vyrastekova, 2006). The cleanliness of the lake in the second round increased, on average, by 14.7 percentage points in response to $:$. Expressing positive emotions, on the other hand, backfired: the farmers realized that they would be able to squeeze out a little more profit and as a result the cleanliness of the lake decreased on average by 6.0 percentage points in response to -$)$. The cleanliness stayed approximately the same (on average, 0.6 percentage points reduction) if the emotions were not expressed. Intriguingly, the reaction of the two farmers on emotions was quite different (Figure 5): while the frowney emoticons led to a similar increase in the usage of conservation technology, smiley emoticons negatively affected the UF/DWUs, but not UFs. This rather striking result suggests that positive emotions signaled that the rewarding party was satisfied with the outcome which encouraged the rewarded party (UF/DWU) to yield to the temptation to be more selfish in the second round.

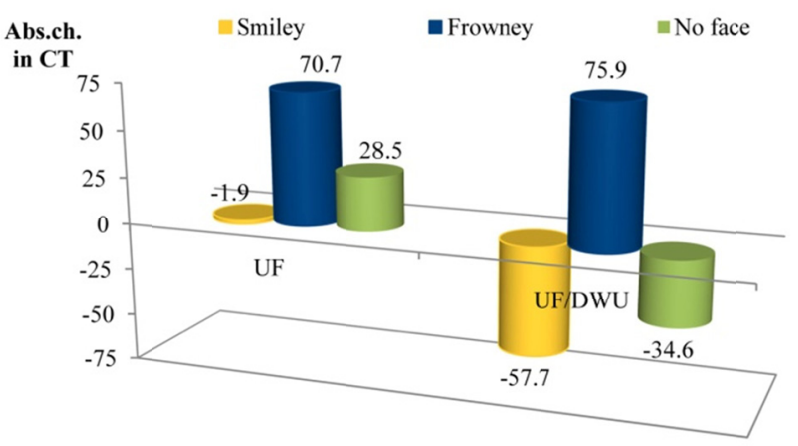

Figure 5. Absolute change in the usage of conservation technology in response to emotional feedback

Description: The figure reflects the absolute change in the level of Conservation Tillage (CT, in acres) chosen by the farmers in Round 2 as compared to Round 1.

The regression analysis (Table 3) provides a more detailed picture regarding the influence of emotions on outcomes in the second round. The dependent variable in Models $4 \& 5$ is the absolute difference between the cleanliness of the lake in the second and the first rounds. Only negative emotions can explain this difference - the coefficient in front of the dummy for $\otimes$ is significant at $1 \%$ (Model 4 ), whereas the one for $:-$ is not. The analysis of the interaction between the treatments and emotions (Model 5) reveals that negative emotions play a significant role only in the SELF-INTEREST FRAME (as the rest of the coefficients are not significant). In this treatment sending a frowning face led, , on average, to an increase in the lake cleanliness by 21.8 percentage points. Coupled with the fact that the first round average cleanliness was $29.4 \%$, this suggests that the expression of negative emotions is extremely effective and can, on its own, guarantee that the DWU gets their 'fair/equal' share of 1000 tokens. The seeming ineffectiveness of the emotional sanctions and rewards in the EMPATHY FRAME was, most likely, driven by the distributions of the average payoffs in the first round which were already almost equal $(1024,1013$, and 963 tokens respectively). In the second round emotional feedback was therefore unable to sway the farmers to give up more of their payoffs in favor of the DWU (in the second round the average payoffs in EMPATHY FRAME were 1018,1016 , and 966 for the UF, UF/DWU, and DWU, respectively).

Models 6-9 are estimated with the difference between the usage of conservation technology by the UF and $\mathrm{UF} / \mathrm{DWU}$ in the second and the first round as the dependent variable. As shown above, for both farmers a negative emotional feedback led to a significant increase in the CT usage only in the SELF-INTEREST FRAME. However, the effect of $: \theta$ on UF/DWU was more pronounced: ceteris paribus the UF/DWU responded by placing 128.1 acres more under CT, while the UF increased CT "only" by 92.3 acres. Given that each of the farmers had a maximum of 500 acres, those numbers are quite high. 
Table 3. Tobit regression with dependent variables "absolute change in round 2 as compared to round 1"

\begin{tabular}{|c|c|c|c|c|c|c|}
\hline & Model 4† & Model 5† & Model 6: & Model $7 \%$ & Model 8: & Model 9: \\
\hline Dependent Variable & \multicolumn{2}{|c|}{ Abs. ch. Cleanliness } & \multicolumn{2}{|c|}{ Abs.ch. CT by UF } & \multicolumn{2}{|c|}{ Abs.ch. CT by UF/DWU } \\
\hline INTERCEPT & -0.612 & -0.612 & 29.43 & 29.38 & -34.62 & -34.61 \\
\hline (:) (dummy) & -5.350 & -1.888 & -31.35 & -16.88 & -25.88 & -2.885 \\
\hline : (dummy) & $15.28 * * *$ & -0.408 & $41.30^{\prime}$ & -19.58 & $111.7^{* * *}$ & 14.62 \\
\hline (;) x EMPATHY FRAME & & -10.36 & & -41.07 & & -67.76 \\
\hline (:) x SELF-INTEREST FRAME & & 13.75 & & 50.00 & & 87.50 \\
\hline : $\mathrm{x}$ EMPATHY FRAME & & 13.34 & & 40.20 & & 93.18 \\
\hline (:) x SELF-INTEREST FRAME & & $21.81^{* * *}$ & & $92.26^{*}$ & & $128.1^{*}$ \\
\hline Log-Likelihood & -245.8 & -241.3 & -372.4 & -370.1 & -382.4 & -379.4 \\
\hline Nagelkerke $R^{2}$ & 0.18 & 0.28 & 0.06 & 0.12 & 0.17 & 0.23 \\
\hline
\end{tabular}

Description: Significance levels: ***-1\%,**-5\%,*-10\%, ${ }^{\prime}-16 \%$. $\dagger$ - the dependent variable is censored between -100 and 100 ; $\$-$ the dependent variable is censored between -500 and 500 . The table shows the results of the regression estimating the influence of the treatment and emotions on the change in the cleanliness of the lake and the level of conservation tillage chosen by the farmers in Round 2 as compared to Round 1.

Result 4. Expressing negative emotions is effective in moving people towards more equal distributions.

From the actions of UFs and UF/DWUs in the second round we get another confirmation of the power of actually "walking-in-the-shoes" of other people: the UF/DWUs are more responsive to social cues than the UFs in terms of initial decisions and reaction on the DWUs' disapproval. All but one coefficient in Models 6-9 are insignificant and thus definite conclusions cannot be made. Nevertheless, we observe that positive coefficients in Models 8 \& 9 are larger than the respective coefficients in Models $6 \& 7$, and all but one negative coefficient are smaller, suggesting higher sensitivity of UF/DWUs as compared to UFs. It is reasonable to expect that with a larger sample size our confidence in this conjecture would increase.

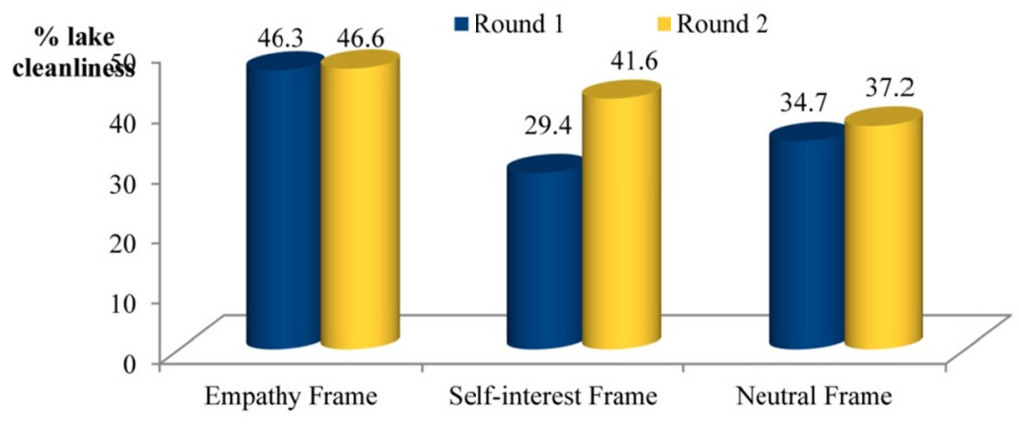

Figure 6 . Average lake cleanliness by round

Description: The figure compares the average lake cleanliness in the two rounds under the three treatments. A lake cleanliness of $50 \%$ provides the DWU with a payoff of 1000 tokens.

On a larger scale the effectiveness of expressing emotions is comparable to the empathetic framing (Figure 6). Neither the non-parametric Kruskal-Wallis test $\left(\chi^{2}(2)=2.40\right.$, p-value $\left.=0.30\right)$ nor the Mann-Whitney-Wilcoxon rank-sum test showed any statistically significant difference between the treatments in the second round. This suggests that explicit emotional feedback, even though not expressed by everyone, works similarly to the implicit appeal to emotions through framing.

\section{Conclusions and Implications}

Three important implications can be derived from our study. First, our experiment supports that priming-oriented framing is highly effective in changing the behavior of subjects. This supports Singer \& Fehr's (2005, p.340) argument that "empathy renders our emotions other-regarding, which provides the motivational basis for other-regarding behavior". Empathy framing leads to an almost equitable distribution of income, whereas self-interest framing leads to more profit-maximizing behavior. Both of these are different from the neutral 
scenario. In line with the comment of a referee on the Alpizar et al. (2008, p.312) paper that "the framing effects do not only cause problems; sometimes they may be seen as an asset for the researcher" we argue that rather than avoiding framing in all experiments we should study its impact as interactions/communications in the field do not happen in neutral language and without context. In particular our results support that environmental policy should appeal to the empathy of polluters.

Second, perhaps not surprisingly, the subjects with a higher stake in the quality of the lake water contributed much more to the cleanliness of the lake than those with no stake. We observe this effect despite the identical Nash equilibrium for both types. This finding is in line with both, the neuroeconomics findings that the degree to which individuals have empathetic feelings depends on the situational factors (Singer, 2009) and the dual-interest and metaeconomics framework (Hayes \& Lynne, 2004; Lynne, 2006) in that the UF/DWUs were placed into the situation of "walking-in-the-shoes-of" downstream water users and, thus, displayed more empathetic behavior than the UFs who could only imagine how it feels. In terms of policy this calls for increased exposure of upstreamers to the negative externalities of their behavior. In contrast to a traditional approach of fully internalizing the externality, our results support the contention that even a minor internalization, maybe even symbolic in nature, may suffice to significantly change behavior. In addition, typically UFs will be downstream to other negative environmental externalities, such as global warming, air pollution, and wind erosion. Pointing out/educating about the similarities of the consequence of their own actions to other people and the impact of these other negative externalities on themselves (asking them to project ownself into that dowsnstream situation) may then help to change the upstreamer's behavior.

Third, negative emotional feedback (non-monetary punishment), although costly, is an effective tool in positively influencing environmental choices. As Xiao \& Houser (2005, p.7401) noted "the desire to express emotions, and constraints on that demand, are a ubiquitous feature of human social interaction" so it is worth utilizing this desire in addition to the standard policies of monetary sanctions and rewards and putting more emphasis on the dual-interest underlying such decisions. Our findings provide additional support for the effectiveness of policies that promote social punishment and public shaming as strategies to achieve lawful and/or cooperative behavior.

\section{Acknowledgements}

The data collection was funded through the USDA-CSREES (program name changed to NIFA) National Integrated Water Quality program. We greatly appreciate the financial support. The experiment was conducted in the Experimental and Behavioral Economics Laboratory at the University of Nebraska-Lincoln. We wish to thank Darin Dolberg (University of Nebraska-Lincoln) for computer support. We also thank Jonathan Bertin (University of Michigan-Dearborn) for his assistance in administering the experiment.

\section{References}

Abbink, K., \& Hennig-Schmidt, H. (2006). Neutral versus loaded instructions in a bribery experiment. Experimental Economics, 9(1), 103-121. http://dx.doi.org/10.1007/s10683-006-5385-z

Alipizar, F., Carlsson, F., \& Johansson-Stenman, O. (2008). Does context matter more for hypothetical than for actual contributions? Evidence from a natural field experiment. Experimental Economics 11(3), 299-314. http://dx.doi.org/10.1007/s10683-007-9194-9

Andreoni, J. (1995). Warm-glow versus cold-prickle: the effects of positive and negative framing on cooperation in experiments. Quarterly Journal of Economics, 110(1), 1-21. http://dx.doi.org/10.2307/2118508

Andreoni, J., Harbaugh, W., \& Vesterlund, L. (2003). The carrot or the stick: rewards, punishments, and cooperation. American Economic Review, 93(3), 983-902. http://dx.doi.org/10.1257/000282803322157142

Balliet, D. (2010). Communication and cooperation in social dilemmas: a Meta-analytic review. Journal of Conflict Resolution, 54(1), 39-57. http://dx.doi.org/10.1177/0022002709352443

Barr, A., \& Serra, D. (2009). The effects of externalities and framing on bribery in a petty corruption experiment. Experimental Economics, 12(4), 488-503. http://dx.doi.org/10.1007/s10683-009-9225-9

Ben-Shakhar, G., Bornstein, G., Hopfensitz, A., \& Van Winden, F. (2007). Reciprocity and emotions in bargaining using physiological and self-report measures. Journal of Economic Psychology, 28(3), 314-323. http://dx.doi.org/10.1016/j.joep.2007.02.005

Benz, M., \& Meier, S. (2008). Do people behave in experiments as in the field?-Evidence from donations. Experimental Economics, 11(3), 268-281. http://dx.doi.org/10.1007/s10683-007-9192-y 
Bochet, O., Page, T., \& Putterman, L. (2006). Communication and punishment in voluntary contribution experiments. Journal of Economic Behavior \& Organization, 60(1), 11-26. http://dx.doi.org/10.1016/j.jebo.2003.06.006

Bosman, R., \& Van Winden, F. (2002). Emotional hazard in a power-to-take experiment. Economic Journal, 112(476), 147-169. http://dx.doi.org/10.1111/1468-0297.0j677

Brandts, J., \& Charness, G. (2000). Hot vs. cold: Sequential responses and preference stability in experimental games. Experimental Economics, 2(3), 227-238. http://dx.doi.org/10.1007/BF01669197

Brosig, J., Weimann, J., \& Yang, C. (2003). The hot versus cold effect in a simple bargaining experiment. Experimental Economics, 6(1), 75-90. http://dx.doi.org/10.1023/A:1024204826499

Cardenas, J. C., \& Stranlund, J., \& Willis, C. (2000). Local environmental control and institutional crowding-out. World Development, 28(10), 1719-1733. http://dx.doi.org/10.1016/S0305-750X(00)00055-3

Carpenter, J., \& Matthews, P. H. (2009). What norms trigger punishment? Experimental Economics, 12(3), 272-288. http://dx.doi.org/10.1007/s10683-009-9214-z

Cookson, R. (2000). Framing effects in public goods experiments. Experimental Economics, 3(1), 55-79. http://dx.doi.org/10.1007/BF01669207

Cubitt, R. P., Drouvelis, M., \& Gächter, S. (2011). Framing and free riding: emotional responses and punishment in social dilemma games. Experimental Economics, 14(2), 254-272. http://dx.doi.org/10.1007/s10683-010-9266-0

Cubitt, R. P., Drouvelis, M., Gächter, S., \& Kabalin, R. (2011). Moral judgments in social dilemmas: How bad is free riding? Journal of Public Economics, 95(3-4), 253-264. http://dx.doi.org/10.1016/j.jpubeco.2010.10.011

Dickinson, D. L. (2001). The carrot vs. the stick in work team motivation. Experimental Economics, 4(1), 107-124. http://dx.doi.org/10.1007/BF01669275

Duffy, J., \& Kornienko, T. (2010). Does competition affect giving? An experimental study. Journal of Economic Behavior \& Organization, 74(1-2), 82-103. http://dx.doi.org/10.1016/j.jebo.2010.02.001

Dugar, S. (2010). Nonmonetary sanctions and rewards in an experimental coordination game. Journal of Economic Behavior \& Organization, 73(3), 377-386. http://dx.doi.org/10.1016/j.jebo.2009.11.003

Fehr, E., \& Gächter, S. (2002). Altruistic punishment in humans. Nature, 415(6868), 137-140. http://dx.doi.org/10.1038/415137a

Fischbacher, U. (2007). z-Tree: Zurich toolbox for ready-made economic experiments. Experimental Economics, 10(2), 171-178. http://dx.doi.org/10.1007/s10683-006-9159-4

Fujimoto, H., \& Park, E. (2010). Framing effects and gender differences in voluntary public goods provision experiments. Journal of Socio-Economics, 39(4), 455-457. http://dx.doi.org/10.1016/j.socec.2010.03.002

Gächter, S., \& Fehr, E. (2000). Cooperation and punishment in public goods experiments. American Economic Review, 90(4), 980-994. http://dx.doi.org/10.1257/aer.90.4.980

Hayes, W. H., \& Lynne, G. D. (2004). Towards a centerpiece for ecological economics. Ecological Economics, 49(3), 287-301. http://dx.doi.org/10.1016/j.ecolecon.2004.01.014

Henrich, J., McElreath, R., Barr, A., Ensminger, J., Barrett, C., Bolyanatz, A., . . . Ziker, J. (2003). Costly $\begin{array}{lllll}\text { punishment across human } & \text { societies. Science, 312(5781), }\end{array}$ http://dx.doi.org/10.1126/science.1127333

Hopfensitz, A., \& Reuben, E. (2009). The importance of emotions for the effectiveness of social punishment. Economic Journal, 119(540), 1534-1559. http://dx.doi.org/10.1111/j.1468-0297.2009.02288.x

Kühberger, A., Schulte-Mecklenbeck, M., \& Perner, J. (2002). Framing decisions: hypothetical and real. Organizational Behavior and Human Decision Processes, 89(2), 1162-1175. http://dx.doi.org/10.1016/S0749-5978(02)00021-3

López-Pérez, R., \& Vorsatz, M. (2010). On approval and disapproval: theory and experiments. Journal of Economic Psychology, 31(4), 527-541. http://dx.doi.org/10.1016/j.joep.2010.03.016

Lynne, G. D. (2006). Toward a dual motive metaeconomic theory. Journal of Socio-Economics, 35, 634-651. http://dx.doi.org/10.1016/j.socec.2005.12.019 
Masclet, D., Noussair, C., Tucker, S., \& Villeval, M. (2003). Monetary and nonmonetary punishment in the voluntary contributions mechanism. American Economic Review, 93(1), 366-380. http://dx.doi.org/10.1257/000282803321455359

Nelissen, R. M. A., \& Zeelenberg, M. (2009). Moral emotions as determinants of third-party punishment: anger, guilt, and the functions of altruistic sanctions. Judgment and Decision Making, 4(7), 543-553.

Nikiforakis, N. (2010). Feedback, punishment and cooperation in public good experiments. Games and Economic Behavior, 68(2), 689-702. http://dx.doi.org/10.1016/j.geb.2009.09.004

Noussair, C., \& Tucker, S. J. (2005). Combining monetary and social sanctions to promote cooperation. Economic Inquiry, 43(3), 649-660. http://dx.doi.org/10.1093/ei/cbi045

Offerman, T. (2002). Hurting hurts more than helping helps. European Economic Review, 46(8), 1423-1437. http://dx.doi.org/10.1016/S0014-2921(01)00176-3

Ostrom, E. (2010). Beyond markets and states: polycentric governance of complex economic systems. American Economic Review, 100(3), 641-672. http://dx.doi.org/10.1257/aer.100.3.641

Ostrom, E., \& Walker, J. (1991). Communication in a commons: cooperation without external enforcement. In Palfrey, T. R. (Ed.), Laboratory research in political economy (pp. 287-322). Ann Arbor: University of Michigan Press.

Park, E. (2000). Warm-glow versus cold-prickle: a further experimental study of framing effects on free-riding. Journal of Economic Behavior \& Organization 43(4), 405-421. http://dx.doi.org/10.1016/S0167-2681(00)00128-1

Sally, D. (1995). Conservation and cooperation in social dilemmas: a Metaanalysis of experiments from 1958 to 1992. Rationality and Society, 7(1), 58-92. http://dx.doi.org/10.1177/1043463195007001004

Sefton, M., Shupp, R., \& Walker, J. M. (2008). The effect of rewards and sanctions in provision of public goods. Economic Inquiry, 45(4), 671-690. http://dx.doi.org/10.1111/j.1465-7295.2007.00051.x

Singer, T. (2009). Understanding others: brain mechanisms of theory of mind and empathy. In Glimcher, P. W., Camerer, C. F., Fehr, E., Poldrack, R. A. (Eds.), Neuroeconomics: Decision Making and the Brain (pp. 251-268). New York: Academic Press.

Singer, T., \& Fehr, E. (2005). The neuroeconomics of mind reading and empathy. American Economic Review, 95(2), 340-345. http://dx.doi.org/10.1257/000282805774670103

Sutter, M., Haigner, S., \& Kocher, M. G. (2010). Choosing the carrot or the stick? Endogenous institutional choice in social dilemma situations. Review of Economic Studies, 77(4), 1540-1566. http://dx.doi.org/10.1111/j.1467-937X.2010.00608.x

Van Soest, D., \& Vyrastekova, J. (2006). Peer enforcement in CPR experiments: The relative effectiveness of sanctions and rewards, and the role of behavioral types. In List, J. A. (Ed.), Using experimental methods in environmental and resource economics (pp. 113-136). Cheltenham: Edward Elgar.

Walker, J. M., \& Halloran, W. A. (2004). Rewards and sanctions and the provision of public goods in one-shot settings. Experimental Economics, 7(3), 235-247. http://dx.doi.org/10.1023/B:EXEC.0000040559.08652.51

Xiao, E., \& Houser, D. (2005). Emotion expression in human punishment behavior. Proceedings of the National Academy of Sciences of the United States of America, 102(20), 7398-7401. http://dx.doi.org/10.1073/pnas.0502399102

\section{Notes}

Note 1. For example, a number of studies of irrigation systems in Nepal as well as in Japan, India and Sri Lanka and studies on forests all over the world reported about their effective farmer-designed systems (Ostrom, 2010).

Note 2. In the hot version of the game visceral factors (including strongly felt emotions) lead to a strong impulse to punish unfair behavior and dominate the decision making process (Brosig et al., 2003).

Note 3. A subject could select to send one of the following three messages: "Your choice was (1) good, (2) neither good nor bad, and (3) bad" (López-Pérez \& Vorsatz 2010, p.532).

Note 4 . The CT (minimal tilling of the land) was presented as a relatively lower profit practice. The CT was also presented as the tillage with relatively mild environmental impact: under $\mathrm{CT}$ the land is disturbed minimally leading to less soil erosion, lower chemical runoff, and overall higher drinking water quality of the downstream rivers and lakes. 
Note 5. The IT was presented as a relatively higher profit tillage practice for the agricultural operator. The IT was also presented as the tillage with relatively higher negative environmental impact: IT leads to soil erosion and greater chemical runoff, and, thus, significantly reduces the drinking water quality of the downstream rivers and lakes.

Note 6. If each of the farmers will choose (independently) to place all their 500 acres of land under $\mathrm{CT}\left(C T_{U F}=\right.$ $C T_{U F / D W U}=500$ ), then the lake cleanliness will be $100 \%$.

Note 7. In Merriam-Webster dictionary empathy is defined as "the action of understanding, being aware of, being sensitive to, and vicariously experiencing the feelings, thoughts, and experience of another of either the past or present without having the feelings, thoughts, and experience fully communicated in an objectively explicit manner" (http://www.merriam-webster.com accessed on 09/04/2011).

Note 8. Nikiforakis (2010) shows that the type of information that is presented to the subjects (e.g. contribution versus earning of the fellow group members in the public goods game) matters for their play. Along similar lines, as noted by the referee of Cubitt, Drouvelis \& Gächter's (2011) paper (footnote 6) it may be problematic to assume that a player is able to differentiate his emotions towards the other two players individually. We showed to the DWU only the outcome (lake cleanliness/pollution) of both choices (but not the actual CT/IT choices), so that this outcome can be judged by the DWU against some "ideal" and/or expected outcome rather than the choices of the two farmers being judged in comparison to each other. This also reflects the real life situation in which the downstream water users can observe only the outcomes of the actions of the upstream farmers, but not their actual actions/choices.

Note 9. Faces were identified as smiley/unhappy and frowny/unhappy based on the common usage of emoticons in electronic communications. Google search for a respective image out of the first 24 faces, 21 (smiley) and 22 (happy) clearly resemble $: ; 19$ (frowney) and 18 (unhappy) clearly resemble $:$. Results of the search are available from the authors upon request.

Note 10. This roughly corresponds to the incentive payments in recent experiments (e.g. Cubitt, Drouvelis \& Gächter, 2011; Duffy \& Kornienko, 2010). Opportunity costs represented by the reported average hourly wage of subjects were $\$ 8.95$, which is calculated without an outlier - one subject recorded an hourly wage of $\$ 1,320$.

Note 11. An odds ratio below one means that the event is less likely to occur than the reference event. 